\title{
Investigation of middle school students' unit coordination levels in mathematics problems involving multiplicative relations ${ }^{1}$
}

Fatma Acar, Middle East Technical University, Turkey, acar.fatma@metu.edu.tr, ORCID: 0000-0001-6545-2970 Şerife Sevinç, Middle East Technical University, Turkey, sserife@metu.edu.tr. ORCID: 0000-0002-4561-9742

\begin{abstract}
This study aimed to identify Turkish middle school students' unit coordination levels in mathematics problems involving multiplicative relations and investigate these unit coordination levels in each grade level. This study was designed as a qualitative case study in which a written instrument developed by Norton and his colleagues (2015) was implemented to 139 middle school students. The student responses were coded based on the rubric developed by Norton and his colleagues (2015), and the unit coordination stages of students at each grade level $\left(5^{\text {th }}, 6^{\text {th }}, 7^{\text {th }}\right.$, and $8^{\text {th }}$ grades $)$ were determined. The findings revealed that almost half of the middle school students operated at the lowest stage of unit coordination (Stage 1 ). While, at $5^{\text {th }} 6^{\text {th }}$, and $7^{\text {th }}$ grades, the number of students operating at Stage 1 was higher than at other unit coordination stages, there were more students at Stage 2 in $8^{\text {th }}$ grade. The number of students operating at Stage 3 was the lowest both at each grade level and in the whole group of 139 middle school students. Hence, very few of the middle school students could operate with three-level units as given and flexibly change between the three-level unit structures. To sum up, the results showed that middle school students could hardly work with and coordinate more than one-level units in mathematics problems requiring multiplicative reasoning. Considering these findings, we suggest conducting more studies examining the unit coordination stages of students and the ways for increasing students' unit coordination levels.
\end{abstract}

Keywords: Unit coordination levels, multiplicative reasoning, mathematics education

Received: 28.08.2019

Accepted: 22.06.2020

Published: 01.01 .2021

\section{INTRODUCTION}

Many topics in middle school mathematics program include problems that involve multiplicative relations between quantities and require abstract operations such as unit coordination (Reynolds \& Wheatley, 1996). Unit coordination refers to creating composite units, switching between units, and relating these composite units in quantitative situations (Norton, Boyce, Phillips, Anwyll, \& Ulrich, 2015). The unit coordination in arithmetic problems involves thinking of a number composed of two numbers, a composite unit (Steffe, 1992). For example, a student uses the same level units in an additive reasoning problem (e.g., eight apples + seven apples $=15$ apples). However, in a multiplicative reasoning problem (e.g., If there are eight apples in each box of seven boxes, how many apples are there altogether?), s/he needs to organize units in different levels (e.g., number of boxes, number of apples in each box, and the total number of apples) (Tzur et al., 2017).

Unit coordination based on switching between units helps students' understanding of various mathematics topics such as whole numbers, fractions, ratio, and proportion (Hackenberg \& Lee, 2015; Hackenberg \& Tillema, 2009; Lamon, 2007). For instance, making sense with units of tens and ones and composing a two-digit number (e.g., 23 composed of 2 tens and 3 ones) indicate using unit coordination in whole number operations and play a significant role in building number sense (Watanabe, 1995). There is also a strong relationship between students' performances on wholenumber units and those on fractional units (Hackenberg, 2007). Besides, Hackenberg (2013) argued that students who struggled in coordinating more than one unit showed also had difficulties in mathematical tasks involving fractions and algebra.

\footnotetext{
${ }^{1}$ This study was presented at the $20194^{\text {th }}$ International Symposium of Turkish Computer and Mathematics Education in İzmir, Turkey
} 
In addition, unit coordination stages of students varied across grade levels, and this difference might be related to students' developmental stages (Ulrich \& Wilkins, 2017). In this sense, there were developmental stages describing students' unit coordination levels. Norton and colleagues (2015) developed a written test to identify students' unit coordination stages. These stages indicated students' mathematical reasoning while organizing units at different levels (Ulrich, 2015). Therefore, these stages inform teachers and curriculum developers about students' mathematical thinking processes.

The role of unit coordination levels in learning mathematics and the possible differences in unit coordination stages across grade levels led us to carry out this study. Not being encountered any research that aimed to identify Turkish students' unit coordination stages puts another layer of significance to this investigation. Since middle school math topics such as numbers, fractions, ratio, and proportion involved multiplicative reasoning, we focused on middle school grade levels; that is, Grade 5-8. Hence, we aimed to examine middle school students' unit coordination stages across grade levels through mathematical tasks involving multiplicative relations. This study addressed the following research question: "What are the unit coordination stages of middle school students (i.e., grades 5-8) in mathematical tasks involving quantities with multiplicative relations?"

\section{THEORETICAL FRAMEWORK}

In recent years, researchers turned their attention to investigating unit coordination levels to make sense with students' mathematical reasoning (Norton et al., 2015; Steffe, 1992; Ulrich \& Wilkins, 2017). In mathematics education, the concept of 'unit' is required to quantify a collection of concrete items and to make sense with the magnitude of an abstract quantity (Ulrich \& Wilkins, 2017). Steffe (1992) viewed a "number" as a mathematical structure composed of composite units. In other words, a number can be seen as a single unit and also a unit of sub-units (Tzur et al., 2017). For instance, 10 represents both a unit of ten and a unit of ten ones (Hackenberg, 2007). Mathematics education researchers have interested in investigating students' construction of composite units and use of these units in operations, which led them to develop unit coordination stages to explain students' mathematical thinking process (e.g., Hackenberg \& Tillema, 2009; Steffe \& Olive, 2010; Ulrich, 2015).

Students develop number sequences that involve nested numbers starting from the early childhood period, and these number sequences constituted a base for multiplicative reasoning in later grades (Steffe, 1992). Multiplicative thinking, one of the most important mathematical thinking processes, is used to describe unit coordination stages of students (Hackenberg, 2010). Hackenberg (2010) hierarchically described the unit coordination levels as Multiplicative Concept 1 (MC1), Multiplicative Concept 2 (MC2), and Multiplicative Concept 3 (MC3). In the first level, students can coordinate two-level units in action. In other words, students use two-level units while counting or relying on physical appearance (Boyce \& Norton, 2016). For instance, to divide 12 by 3 , MC1 students count from 1 to 12 and keep track of units of 3 by counting 1, 2, 3, and 4. On the other hand, MC2 students maintain two-level units and coordinate three-level units in action. In the same problem, MC2 students can think there are two 3s in 6 and two $6 \mathrm{~s}$ in 12; then, it would be four (i.e., 2 times 2) $3 \mathrm{~s}$ in 12 (Boyce \& Norton, 2016). On the highest stage, students can maintain three-level units. MC3 students can respond as 12 very quickly without physically partitioning and iterating. They can internalize 12 as twelve units of one unit, three units of four units in each, and four units of three units in each simultaneously and switch between units.

Norton and colleagues (2015) categorized these levels of multiplicative concepts on three stages, namely, Stage 1, Stage 2, and Stage 3. Students on the first stage have not yet internalized the multiplicative relations between composite units and considered composite units as a collection of units of one. When multiplicative relation between the lengths of the bars are given (see Figure 1), students physically iterate one of the bars to create the other one, relying on physical appearance instead of using the multiplicative relations given in the problem numerically. 


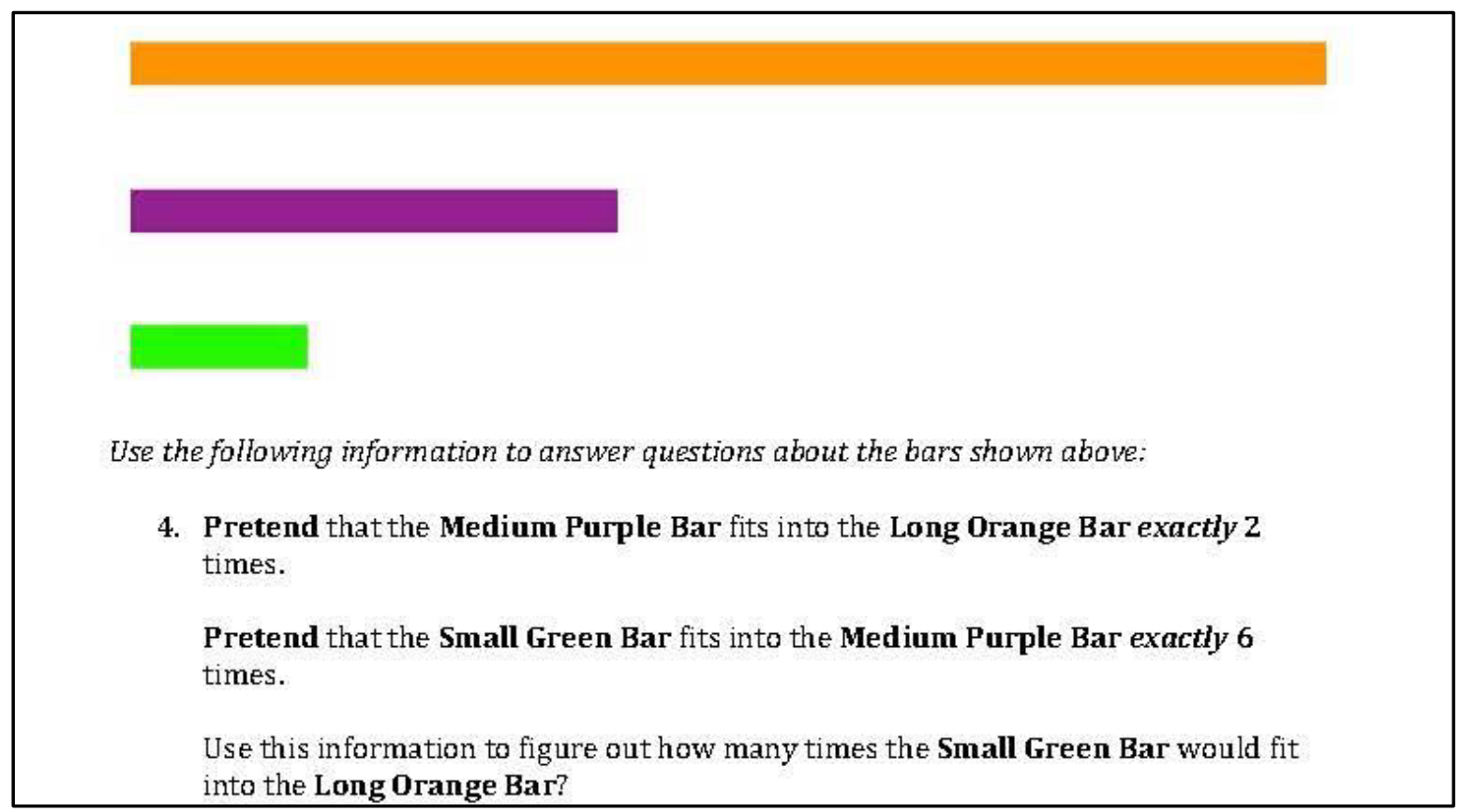

FIGURE 1. Sample item in unit coordination test (Norton et al., 2015, p.131)

On Stage 2, students can maintain the multiplicative relation between two-level units; but they need to physically or mentally iterate the units to use three-level units. For instance, Stage 2 student thinks the medium purple bar in Figure 1 as a unit of six units and iterates it two times to create the long orange bar. At Stage 3, based on the given multiplicative relations, students can figure out the longest bar as a unit of units of units (i.e., a unit of two units of 6 units in each) without physical or mental iterations. Table 1 summarizes the three-level unit coordination at each stage (Norton et al., 2015).

Table 1. Stages of units coordination (Norton et al., 2015, p. 113)

\begin{tabular}{lll}
\hline & Students' Unit Structures & Students' Reasoning on the Bar Task \\
\hline Stage $\mathbf{1}$ & $\begin{array}{l}\text { Students can take one level of units } \\
\text { as given and may coordinate two } \\
\text { levels of units in activity. }\end{array}$ & $\begin{array}{l}\text { Students mentally iterate the short bar, imagining how } \\
\text { many times it would fit into the longer bar. This activity } \\
\text { might be indicated by head nods or sub-vocal counting. }\end{array}$ \\
\hline Stage $\mathbf{2}$ & $\begin{array}{l}\text { Students can take two levels of units } \\
\text { as given, and may coordinate three } \\
\text { levels of units in activity. }\end{array}$ & $\begin{array}{l}\text { Students mentally iterate the medium bar four times, } \\
\text { with each iteration representing a 3. This activity might } \\
\text { be indicated by the student uttering "3, 3, 3, and 3; 12." }\end{array}$ \\
\hline Stage $\mathbf{3}$ & $\begin{array}{l}\text { Students can take three levels of } \\
\text { units as given, and can thus flexibly } \\
\text { switch between three-level } \\
\text { structures. }\end{array}$ & $\begin{array}{l}\text { Students immediately understand that there are four } \\
\text { threes in the long bar. This assimilation of the task might } \\
\text { be indicated by an immediate response of "12," } \\
\text { buttressed by an argument that 12 is four 3s. }\end{array}$ \\
\hline
\end{tabular}

There are several studies in mathematics education literature investigating students' unit coordination stages and how these stages played a role in students' understanding other math topics (e.g., Hackenberg, Aydeniz, Jones, \& Borowski, 2017; Hackenberg, Jones, Eker \& Creager, 2017; Ulrich \& Wilkins, 2017; Zwanch, 2019). Some of these studies pointed out that the difficulty in coordinating two- and three-level units was one of the main reasons for the weak performances in students' mathematics learning (Hackenberg, 2013; Hackenberg \& Tillema, 2009; Norton \& Boyce, 2013; Steffe \& Olive, 2010). Specifically, algebraic equations involving improper fractions in the middle school 
mathematics curriculum required thinking improper fractions as a unit of some amount of unit fractions, and students who could not coordinate three-level units had difficulties in solving these equations (Ulrich, 2015). Similarly, in another research, researchers found that Stage 1 and Stage 2 students, who could not maintain three-level units, could not develop reciprocal reasoning and could not write equations involving the reciprocal relationship between two unknown quantities (Hackenberg \& Sevinç, under review). Furthermore, it was observed that as students' unit coordination stages increase, they could write correct algebraic equations involving multiplicative relations between two unknown quantities (Zwanch, 2019). Hackenberg and colleagues (2017) also found that almost half of the students could coordinate three-level units and express the multiplicative relations involving fractions more easily. Besides, other students could only coordinate two-level units and therefore had difficulties in expressing the multiplicative relations and tended to use numerical examples to make sense with the multiplicative situations.

Although we have not encountered any study investigating unit coordination levels of students in Turkey, some focused on multiplicative and proportional reasoning and indirectly dealt with unit coordination (e.g., Akkuş Çıkla \& Duatepe, 2002; Toluk Uçar \& Bozkuş; 2016). Toluk Uçar and Bozkuş (2016) studied 4-7th grade students' performances on problems involving additive and multiplicative relations. They found that only $3 \%$ of the students could identify the additive and multiplicative reasoning situations and solve the problems correctly. The researchers also observed that while the $4^{\text {th }}, 5^{\text {th }}$, and $6^{\text {th }}$ graders often tended to use addition as a problem-solving strategy, $7^{\text {th }}$ graders could use multiplicative reasoning in their solutions. In this regard, we believe that the study in which we aimed to identify middle school students' unit coordination stages would constitute an empirical foundation to understand Turkish students' difficulties in learning mathematics.

\section{METHODS}

Since we aimed to identify 5-8th grade students' unit coordination stages and understand how these students use unit coordination to solve problems requiring multiplicative reasoning, we designed a qualitative case study using a structured coding frame. A case study is a qualitative research approach that investigates a case thoroughly (i.e., a group, a subject, or a framework) around a framework (Creswell, 2007; Yin, 2003). This study is a multi-case study, and each grade level in the middle school (i.e., 5, 6, 7, and 8th grades) is determined as a case concerning unit coordination levels.

\section{Participants}

139 middle school students in Istanbul, one of the metropolitan cities in Turkey, were selected through convenient sampling. Since there were two classes in the $5^{\text {th }}, 6^{\text {th }}$, and $7^{\text {th }}$ grades, we collected data from all students in these grade levels. However, there were four $8^{\text {th }}$ grade classes in the school; we randomly selected two of them to involve in the study. All students were invited to the study, and their voluntary participation was asked. Furthermore, we informed students' parents about the study and gathered signed consent forms from the parents. Table 2 below presents the number of participating students across grade levels and gender.

\section{Data Collection Tool: Unit Coordination Test}

We utilized the Unit Coordination Test developed by Norton and colleagues (2015) to identify middle school students' unit coordination stages based on their written responses (see Appendix A). This test involves seven tasks involving multiplicative relations between quantities. In each task, three bars in different lengths and colors were given, the multiplication relation between two pairs of the bars was stated numerically, and the multiplicative relation between the third pair was asked. In other words, students were asked to find the unknown multiplicative relation using the known ones and show the solution strategies explicitly. We analyzed students' responses using the evaluation rubric developed by Norton and colleagues (2015). 
Table 2. Number of students across grade level and gender

\begin{tabular}{llll}
\hline Grade Level & Number of Girls & Number of Boys & Total Number of Students \\
\hline Grade 5 & 13 & 12 & $25(18 \%)$ \\
Grade 6 & 10 & 11 & $21(15.1 \%)$ \\
Grade 7 & 24 & 28 & $52(37.4 \%)$ \\
Grade 8 & 22 & 19 & $41(29.5 \%)$ \\
\hline Total & $69(49.6 \%)$ & $70(50.4 \%)$ & $139(100.0 \%)$ \\
\hline
\end{tabular}

Hackenberg, Norton, and Wright (2016) explained the tasks in the Unit Coordination Test and indicators of unit coordination stages in detail. In the first two tasks, students were expected to find how many medium bars fit into the long bar and how many small bars fit into the medium bar, respectively. While the responses between 2 and 4 were acceptable for Task 1 , the responses between 3 and 5 were reasonable for Task 2. To answer Task 3 that asked how many small bars would fit into the long bar, students were expected to use the answers they found in the first two tasks.

The tasks in the rest of the Unit Coordination Test involved the bars, the lengths of which purposefully did not reflect the multiplicative relations stated in the tasks. Therefore, these tasks were considered important to determine whether student responses reflected Stage 2 or Stage 3. For example, in Task 4, the multiplicative relations between small and medium bars and between medium and long bars were given numerically, and finding how many small bars would fit into the long bar required to multiply given relations. In Tasks 5 and 6, a bar was determined as a reference bar, and the multiplicative relations between this bar and the other two bars were given numerically. For instance, in Task 5, the long bar was selected as a reference bar. The task numerically stated how many medium and how many small bars fit into the long bar and asked the relation between the other pair of bars (i.e., how many small bars would fit into the medium bar). Task 6 presented how many small bars were needed to make the long bar and how many for the medium bar and asked how many medium bars would fit into the long bar. These two tasks involved reverse multiplicative reasoning and required students to use division, contrary to previous tasks. Similarly, the last task involved reverse multiplicative reasoning but not a whole number relation. In other words, a fractional amount of one unit was needed to make the other bar.

Students who (i) relied on the visual appearance of the bars rather than using the numerical relations stated in the task, (ii) doing addition or subtraction rather than multiplication (on the $3^{\text {rd }}$ and $4^{\text {th }}$ tasks) and division (on the $5^{\text {th }}, 6^{\text {th }}$, and $7^{\text {th }}$ tasks) with the given relations between units, (iii) could not respond, or (iv) stated that they did not understand the task were identified at Stage 1. If students' drawings and/or explanations indicated that they created composite units using one of the given relations between the units, their unit coordination stage was considered either Stage 2 or Stage 3. Students who drew or explain more than one two-level unit coordination were identified at Stage 2. In other words, Stage 2 students could maintain two-level units, although they could coordinate three-level units. These students could represent two-level unit relations in two different drawings separately. Instead, students who could draw a single picture involving a unit of unit of units were determined at Stage 3. Therefore, students' explanations, in addition to multiplication and division operations and drawings, were considered as indicators of Stage 3.

Norton and colleagues (2015) also developed an evaluation rubric considering their conjectures as they were developing the tasks and related literature on indicators of unit coordination levels (e.g., Hackenberg, 2010). During this process, researchers asked teachers and other researchers to assess students' unit coordination stages by using both written assessment and clinical interviews. The researchers then compared these assessments to test the validity and reliability of the written 
test and evaluation rubric. In addition, to test the inter-rater reliability, they compared unit coordination levels identified by different researchers. The inter-rater reliability between two researchers who assessed 47 students' unit coordination stages separately was found as $80.9 \%$ (Norton et al., 2015). For the reliability, Spearman rho statistics was calculated ( $r=0.808)$. Besides, the Kappa statistics, 0.705 , indicated sufficient reliability. After this validity and reliability testing processes, researchers made necessary revisions on the evaluation rubric.

To use the Unit Coordination Test in this study, we first contacted Anderson Norton, who was one of the researchers in the research team that developed the test and asked for permission. Second, two mathematics education researchers translated the test from English to Turkish. Third, the translated test was administered to ten $5-8^{\text {th }}$ grade students to test the clarity of the tasks. Forth, we revised the translation of the test based on students' questions and their responses. Lastly, we asked an experienced mathematics education professor to check the latest translation, and we finalized the translated version considering her suggestions.

\section{Data Analysis Procedure}

The first author implemented the Unit Coordination Test to 5-8 $8^{\text {th }}$ grade students (i.e., 139 students in total) in a middle school in Istanbul during the Spring semester. Prior to the implementation, students were informed about the study and ethical considerations such as that their information would not be shared with anyone, and anonymous responses will be used only in academic publications. Besides, students were asked not to provide their names on the test. Instead, we gave an ID number to each student's test, and therefore no identifying information was collected. The Unit Coordination Test was administered in a one-class period (i.e., 40 mins.), and additional time was provided for students who needed it. Since students' drawings and explanations were important, students were reminded to show their ways of thinking through explanations or drawings on the paper.

The data was coded in a qualitative data analysis software called MAXQDA (VERBI Software, 2017) through the rubric developed by Norton and his colleagues (2015). We first evaluated each task separately based on the indicators of the unit coordination levels and determined students' unit coordination stages at each task. Since the first three tasks were related to each other, they were considered as one group. Particularly, Task 3 was used to identify the unit coordination stage for this group. When we finish coding each task separately, the dominant stage appeared on the test was determined as the overall unit coordination stage of the students. During the coding process, particularly when determining the overall unit coordination stage of the students, two researchers discussed the indicators and reached a consensus for each student.

\section{FINDINGS}

In this section, we introduce the findings that show 139 middle school students' unit coordination stages across grade levels (i.e., 5-8 ${ }^{\text {th }}$ grades).

The analysis of students' responses showed that there were 62 students (44.6\%) operating at Stage 1 of unit coordination. These students could not assimilate the multiplicative relationship between the units, and they operate with units of ones. The number of students operating at Stage 2 was 66 (47.5\%), the highest percentage across all stages. They could take two levels of units as given in multiplicative situations, and they carried out some activities such as drawing and iterating the units to establish the third level of units. The number of students operating at Stage 3 was 11 (7.9\%), the lowest percentage among the stages. These students demonstrated that they could assimilate and immediately explain the given relations in three levels of units. These results were summarized in Table 3.

As seen in Table 3, we observed that there were students at each unit coordination stage in each grade level, and the least number of students was at Stage 3 in each grade level. While the students operating at Stage 1 were more in the fifth, sixth, and seventh grades, more students were operating at Stage 2 within eighth graders. Table 3 also showed that the percentage of students at 
Stage 1 decreases as the grade level increases. The number of students operating at Stage 2 increased gradually from grade 5 to grade 8 . The number of students performing at Stage 3 was the lowest in each grade level, and the number of students at this stage did not show an increase across grade levels. The number of Stage 3 students decreased from the fifth grade to sixth grade and from the seventh grade to eighth grade but increased from the sixth grade to seventh grade. In the following sections, we presented the unit coordination stages of students at each grade level, supported by sample student responses.

Table 3. The unit coordination stages of middle school students

\begin{tabular}{lllll}
\hline Grade Level & \multicolumn{4}{l}{ Stages of Unit Coordination } \\
\hline & Stage 1 & Stage 2 & Stage 3 & Total \\
\cline { 2 - 5 } $\mathbf{5}$ & $13(52.0 \%)$ & $9(36.0 \%)$ & $3(12.0 \%)$ & $25(18.0 \%)$ \\
$\mathbf{6}$ & $10(47.6 \%)$ & $10(47.6 \%)$ & $1(4.8 \%)$ & $21(15.1 \%)$ \\
$\mathbf{7}$ & $25(48.1 \%)$ & $22(42.3 \%)$ & $5(9.6 \%)$ & $52(37.4 \%)$ \\
$\mathbf{8}$ & $14(34.1 \%)$ & $25(61.0 \%)$ & $2(4.9 \%)$ & $41(29.5 \%)$ \\
\hline Total & $62(44.6 \%)$ & $66(47.5 \%)$ & $11(7.9 \%)$ & $139(100 \%)$ \\
\hline
\end{tabular}

\section{$5^{\text {th }}$ Grade Students' Unit Coordination Stages}

The unit coordination test was implemented to 25 fifth grade students. We found that 13 of these students (52.0\%) demonstrated Stage 1; nine students (36.0\%) demonstrated Stage 2, and three students $(12.0 \%)$ demonstrated Stage 3 indicators.

While determining the overall unit coordination stages of fifth-grade students, we observed that the responses of 21 students (84\%) indicated the same unit coordination level in all tasks. Hence, this dominant stage was determined as the overall unit coordination level. Besides, the answers of three students involved Stage 2 and 3 indicators, and one student's response indicated Stage 1 and 2. These students' overall unit coordination stages were determined according to the most frequent stage appeared in their tests. The student who demonstrated Stage 1 and 2 indicators was evaluated at Stage 1. Two of three students who have both Stage 2 and 3 indicators were identified as Stage 2 and one at Stage 3. Specifically, students' responses to Tasks 5, 6, and 7 were distinctive in making decisions whether they operated at Stage 2 or 3. As mentioned earlier, the common feature of these tasks was using given multiplicative relationships and reversing the multiplicative reasoning.

Table 4. Fifth graders' unit coordination stages

\begin{tabular}{llll}
\hline \multicolumn{4}{c}{ Unit Coordination Stages } \\
\hline Tasks & Stage 1 & Stage 2 & Stage 3 \\
\hline $\mathbf{1 - 3}$ & $14(56 \%)$ & $11(44 \%)$ & \\
$\mathbf{4}$ & $11(44 \%)$ & $13(52 \%)$ & $1(4 \%)$ \\
$\mathbf{5}$ & $13(52 \%)$ & $7(28 \%)$ & $5(20 \%)$ \\
$\mathbf{6}$ & $13(52 \%)$ & $9(36 \%)$ & $3(12 \%)$ \\
$\mathbf{7}$ & $16(64 \%)$ & $6(24 \%)$ & $3(12 \%)$ \\
\hline Overall Assessment & $13(52 \%)$ & $9(36 \%)$ & $3(12 \%)$ \\
\hline
\end{tabular}

The analysis showed that fifth graders mostly performed at Stage 1 in almost all tasks in the test. In addition, the number of students operating at Stage 3 was the lowest in all tasks. As seen in Table 4, the unit coordination levels of fifth-graders gradually decreased from Task 4 to Task 7, the 
distinctive tasks in determining Stage 2 and 3. This result pointed out that the fifth graders could not assimilate or explain the multiplicative relationship within three-level unit structures. To decide on the overall unit coordination stages of students, students' responses in Task 5, 6, and 7 appeared critical since they involve reverse multiplicative reasoning.

The students' drawings showed that Stage 1 students mostly relied on the length of the bars appeared on the paper rather than using given multiplicative relations. We also observed that some students did not consider the pre-drawn small bar while counting the iterated units they drew. The student response in Figure 2 illustrates a Stage 1 student's response to Task 5.

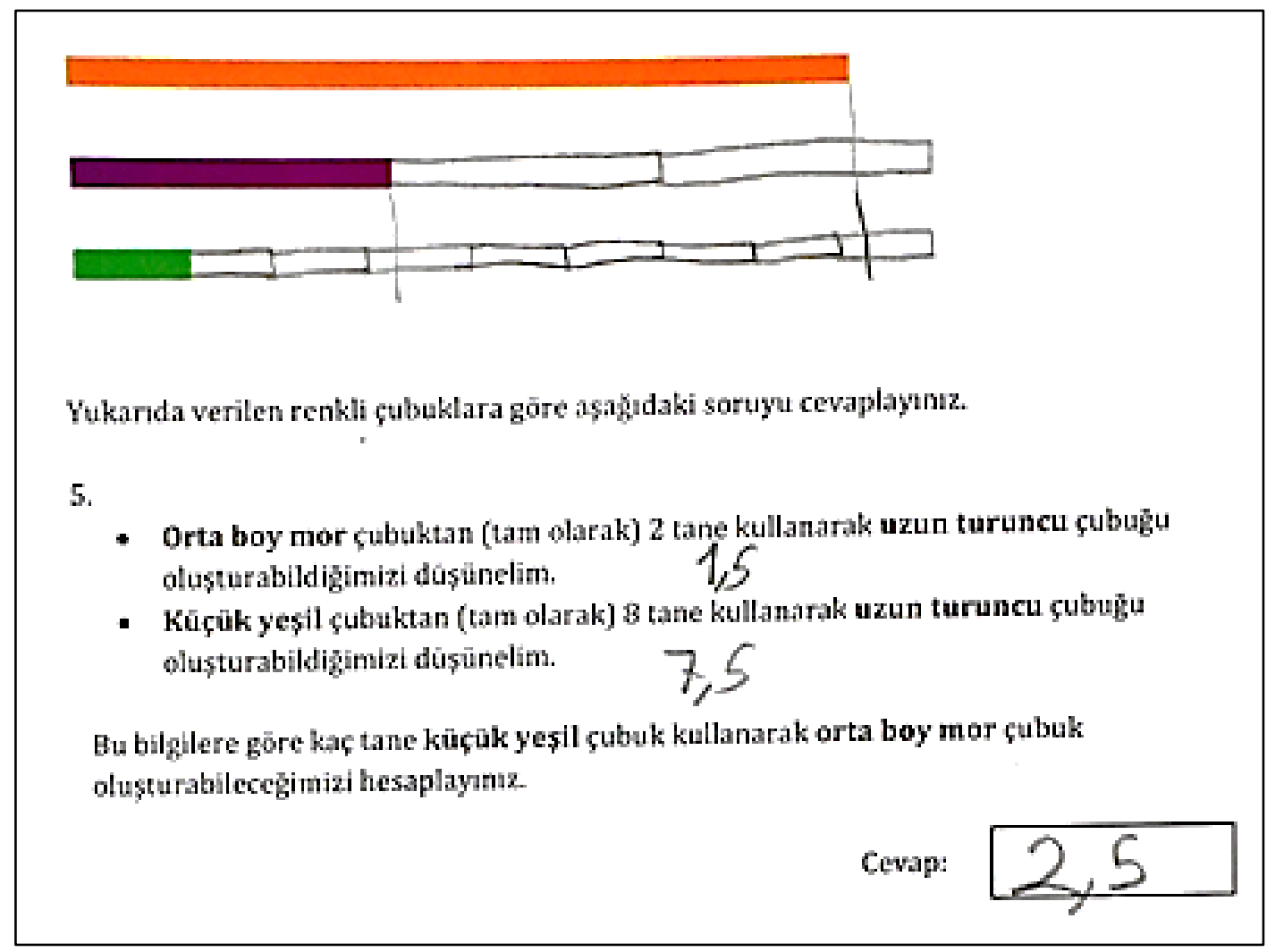

FIGURE 2. A fifth grader's response at Stage 1 in Task 5

As seen in this sample student response, the student relied upon the appearance of bars rather than using the given relations. Moreover, the student did not count the first bar given while he was counting the iterated units that $\mathrm{s} /$ he drew next to the given bar. We observed similar responses in other Stage 1 students. Also, Stage 1 students added or subtracted numbers given in the task rather than multiplying or dividing.

On the other hand, almost all students at Stage 2 used multiplication or division operations without making any justification, explanation, or drawing. Figure 3 shows a Stage 2 student's response that involved division operation but no further explanation of why he divided the given numbers. Besides, there were some students who used given two-level unit relations and provided explanations. In Figure 4, a sample student response at Stage 2 showing the coordination of threelevel units by taking multiple two-level relations as given. 


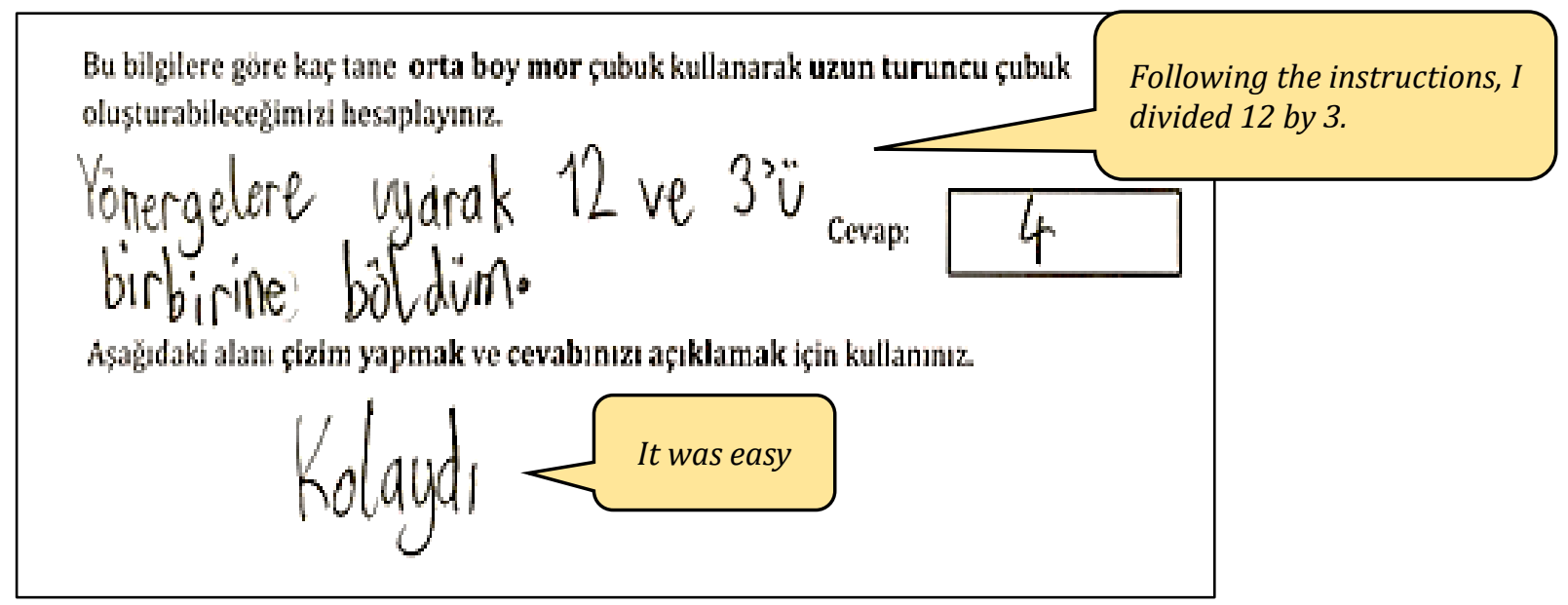

FIGURE 3. A fifth grader's response at Stage 2 in Task 6.

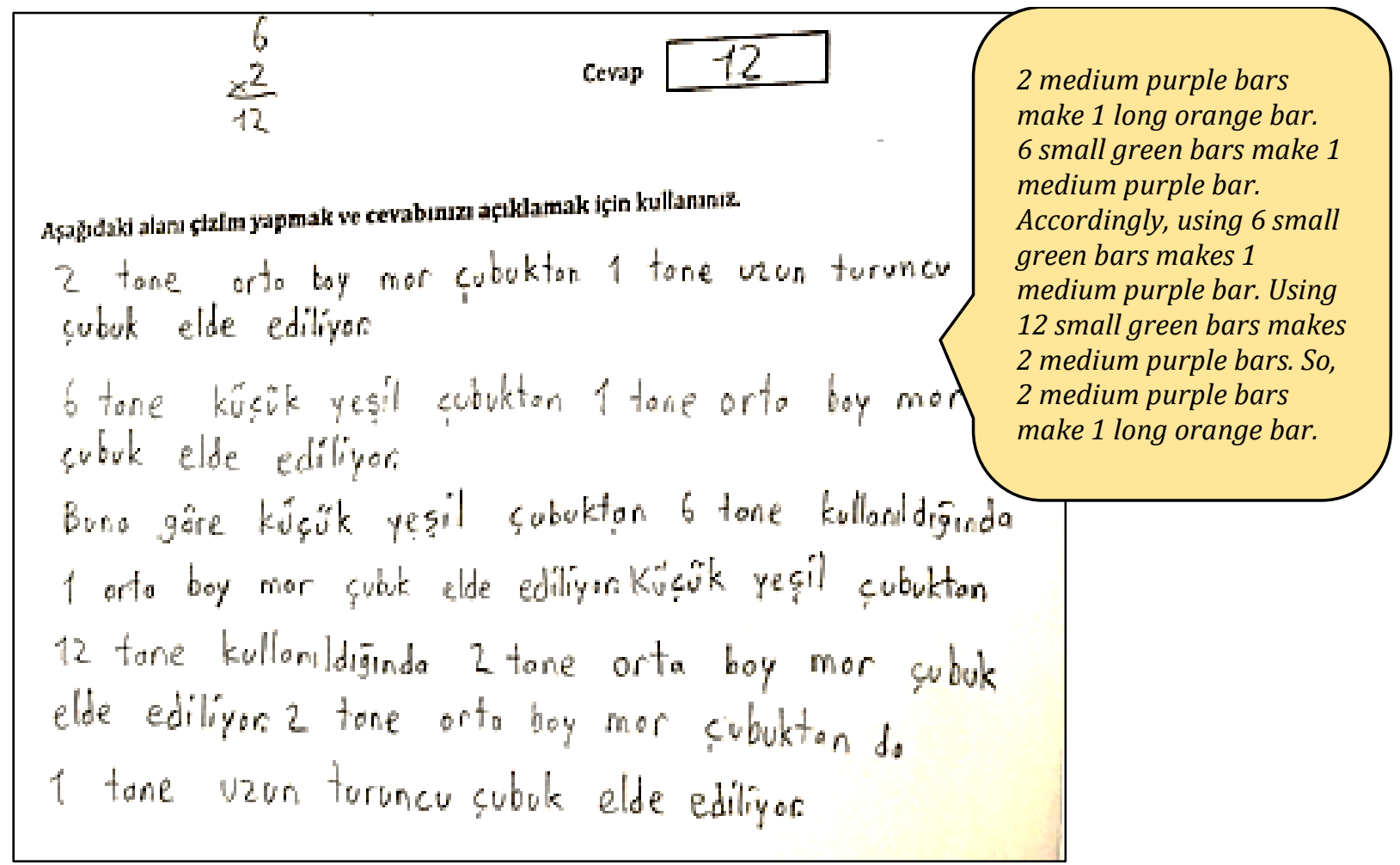

FIGURE 4. $A$ fifth grader's response to Task 4

As seen in Figure 4, iterating a medium unit consisting of six small units two times formed 12 small units; that is, two medium units; therefore, one long unit. This response involved multiple two-level unit relations and therefore indicated Stage 2.

On the contrary, students at Stage 3 of unit coordination could draw three-level unit relations at once and provide justifications revealing their assimilation of given relations into a three-level structure. Tasks 5, 6, and 7 played a significant role in characterizing students' stages of unit coordination because they require reversing multiplicative reasoning. In Figure 5, we provide the answers of two students performing at Stage 3 of unit coordination in Task 7. 

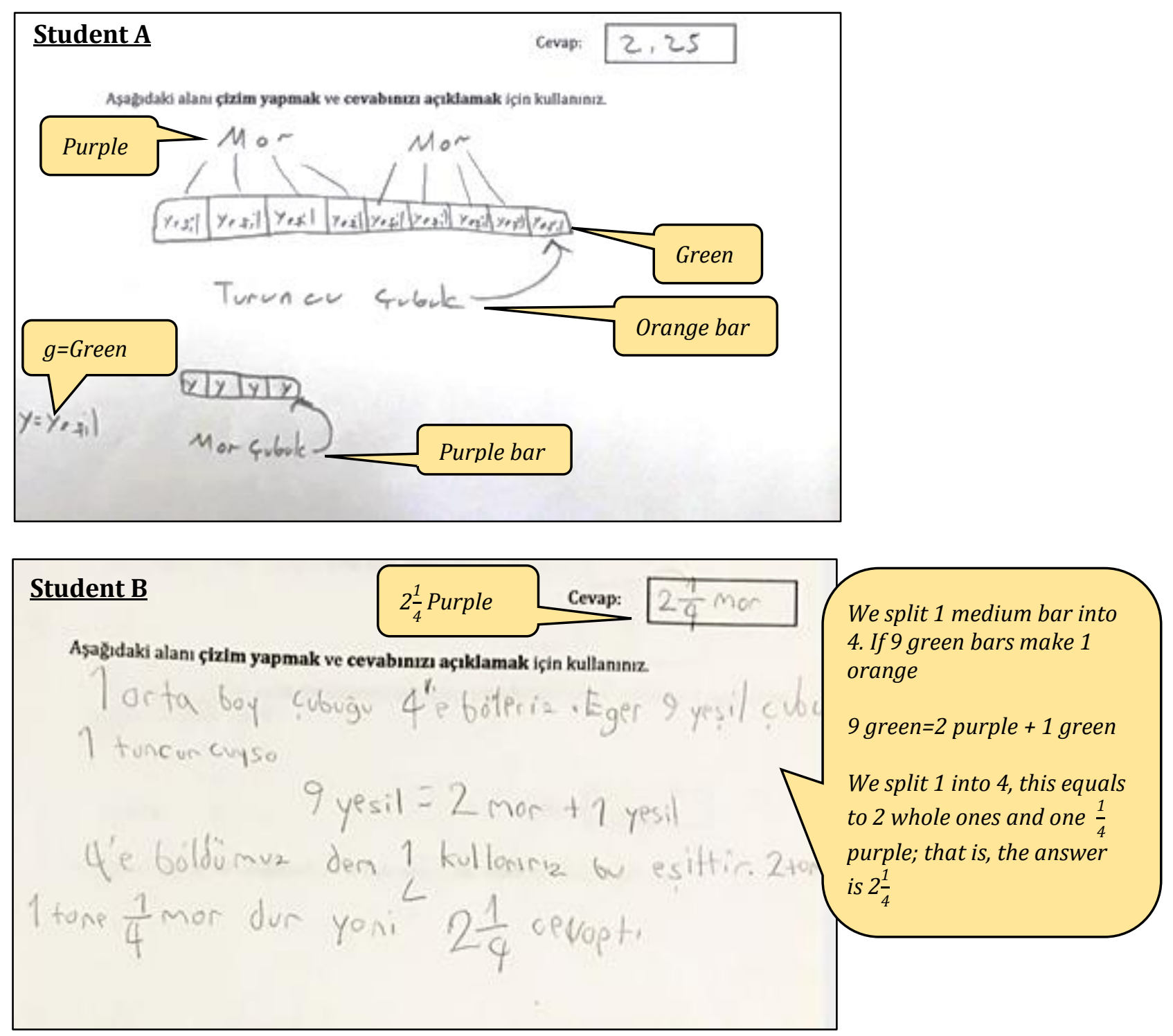

FIGURE 5. Two fifth graders' responses indicating Stage 3 in Task 7

In Figure 5, student A showed three-level units at once on his drawing, so operated at Stage 3 of unit coordination. Student B justified why he used division operation based on the part-whole relationship and maintained a single three-level relation.

\section{$6^{\text {th }}$ Grade Students' Unit Coordination Stages}

Among 21 sixth grade students participating in the study, 10 (47.6\%) students were identified as Stage 1, $10(47.6 \%)$ students were operating at Stage 2, and one (4.8\%) student was identified at Stage 3.

While determining the overall unit coordination levels of sixth graders, we observed that 13 students' responses indicated the same stage in all tasks, and this stage was determined as their overall unit coordination stage. Nine of those students were operating at Stage 1, and four of them were identified as Stage 2 in all tasks. Other students' responses involved indicators of multiple stages in different tasks. Specifically, three students responded at Stages 2 and 3; four students at Stages 1 and 2, and one student at Stages 1,2, and 3. The student who reflected all three levels of unit 
coordination during the task-by-task analysis was determined as operating at Stage 2 in the overall assessment. In the overall assessment process, we focused on the dominant stage and distinctive tasks (i.e., tasks 5, 6, and 7).

The task-by-task assessment indicated that Stage 1 was more prominent in nearly all tasks. In other words, sixth-graders mostly relied on the appearance of the bars shown on the paper rather than using given multiplicative relations and/or used addition or subtraction of the given relations. As seen in Table 5, the percentage of responses indicating higher stages decreased towards the end of the test.

Table 5. Sixth graders' unit coordination stages

\begin{tabular}{llll}
\hline \multicolumn{4}{l}{ Unit Coordination Stages } \\
\hline Tasks & Stage 1 & Stage 2 & Stage 3 \\
\hline $\mathbf{1 - 3}$ & $9(42.9 \%)$ & $12(57.1 \%)$ & \\
$\mathbf{4}$ & $12(57.1 \%)$ & $9(42.9 \%)$ & $0(0 \%)$ \\
$\mathbf{5}$ & $10(47.6 \%)$ & $7(33.3 \%)$ & $4(19.1 \%)$ \\
$\mathbf{6}$ & $14(66.7 \%)$ & $7(33.3 \%)$ & $0(0 \%)$ \\
$\mathbf{7}$ & $16(76.2 \%)$ & $4(19.0 \%)$ & $1(4.8 \%)$ \\
\hline Overall Assessment & $10(47.6 \%)$ & $10(47.6 \%)$ & $1(4.8 \%)$ \\
\hline
\end{tabular}

In most of the Stage 2 responses, the students only used the given numbers in the tasks and did multiplication or division without any explanation and justification. Besides, some students showed the iteration of units on drawings or expressed that they performed mental iteration, although they did not do any calculation. For example, the student response to Task 3 shown in Figure 6 indicated correct multiplicative reasoning that was shown by the iteration of units and repeated addition.

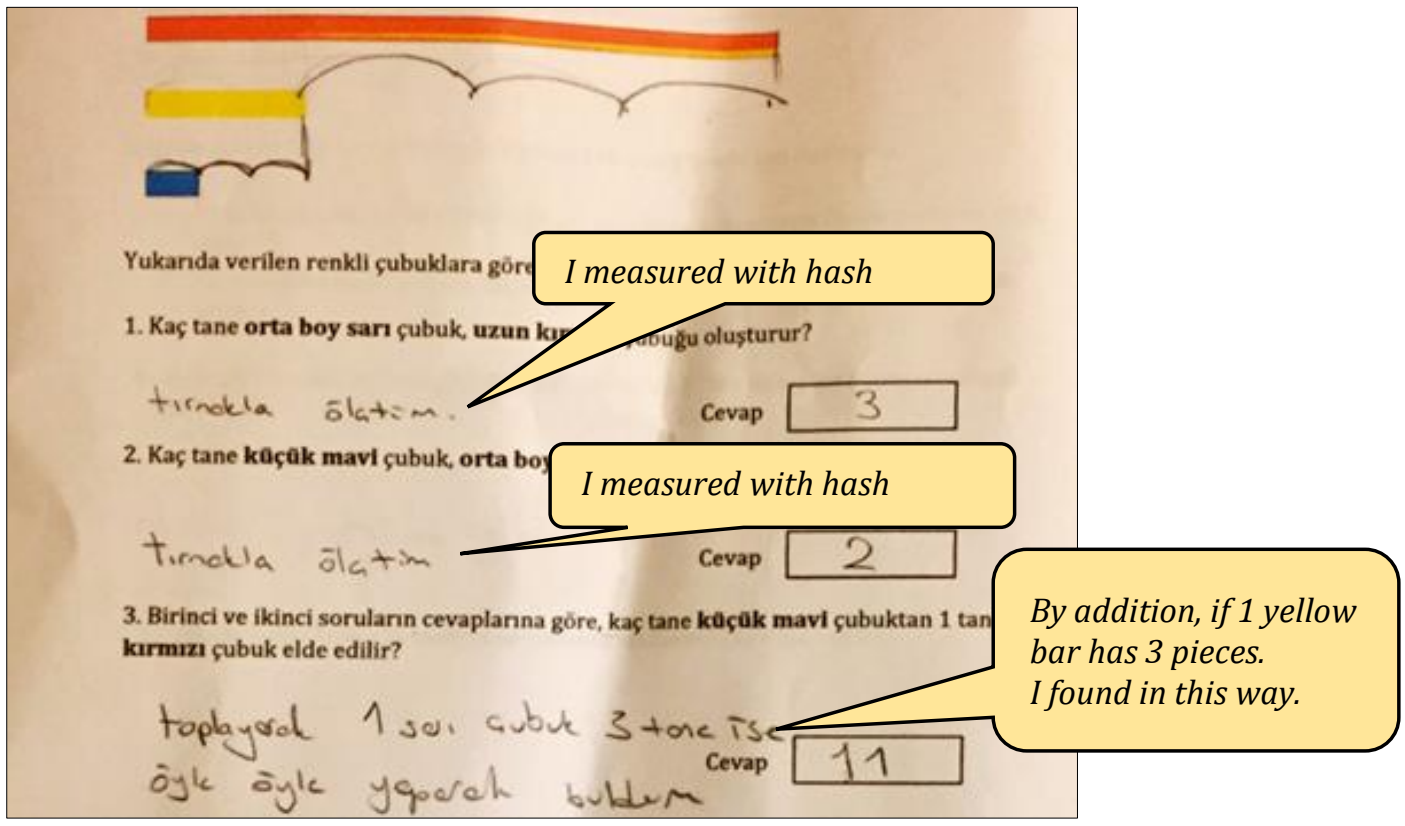

FIGURE 6. A sixth grader's response to Task 3 indicating Stage 2 
This student found 11 as the answer, although the correct answer was 12 . S/he found 11 because $\mathrm{s} /$ he did not take into account the given first bar while adding units of threes and added the last composite unit as a unit of 2 (i.e., $3+3+3+2=11$ ). As seen in this response, the case of not counting the first pre-given bar was observed in sixth-grade students as well as in the fifth graders. Figure 7 demonstrates another Stage 2 student's response using two levels of units as given and coordinating three levels of units in action. In Task 4, the student found the multiplicative relationship between green and orange bars by adding six two-times (i.e., two units of six units of green), using the information that six green bars fit into the one purple bar and two purple bars fit into the one orange bar.

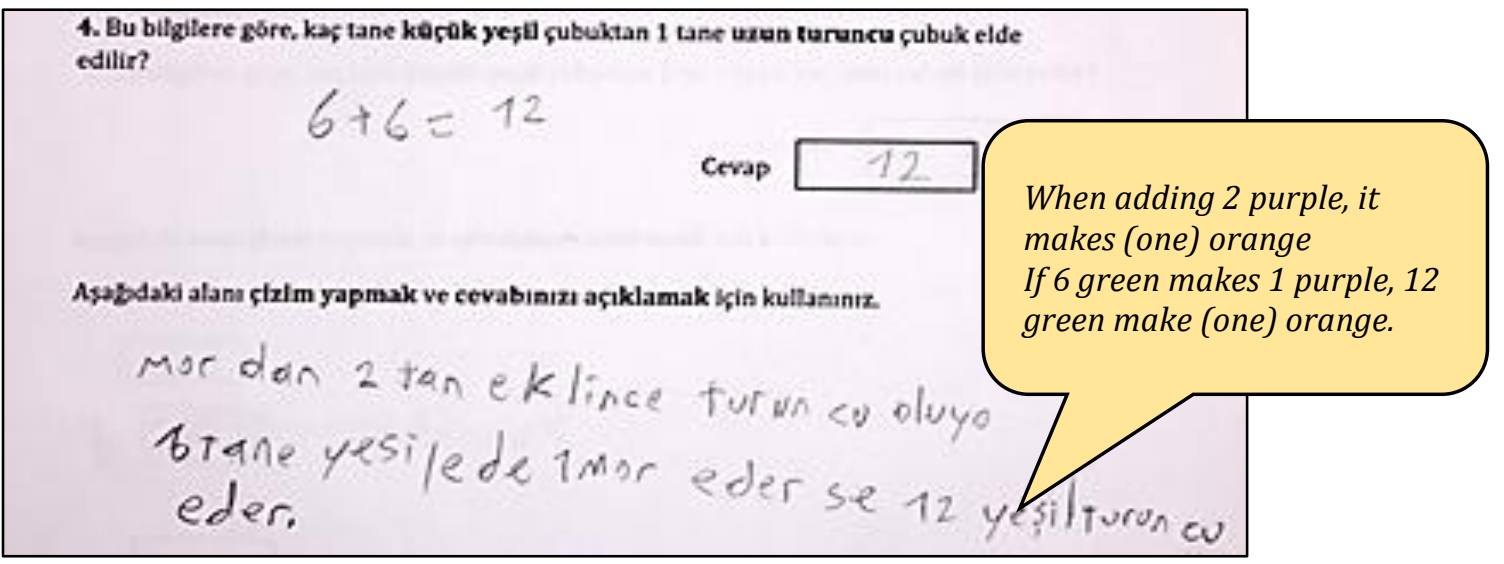

FIGURE 7. A sixth grader's response to Task 4 indicating Stage 2 of unit coordination

The responses indicating Stage 3 included students' explanations of why they did a particular operation. A sample student response to Task 5 was given in Figure 8.

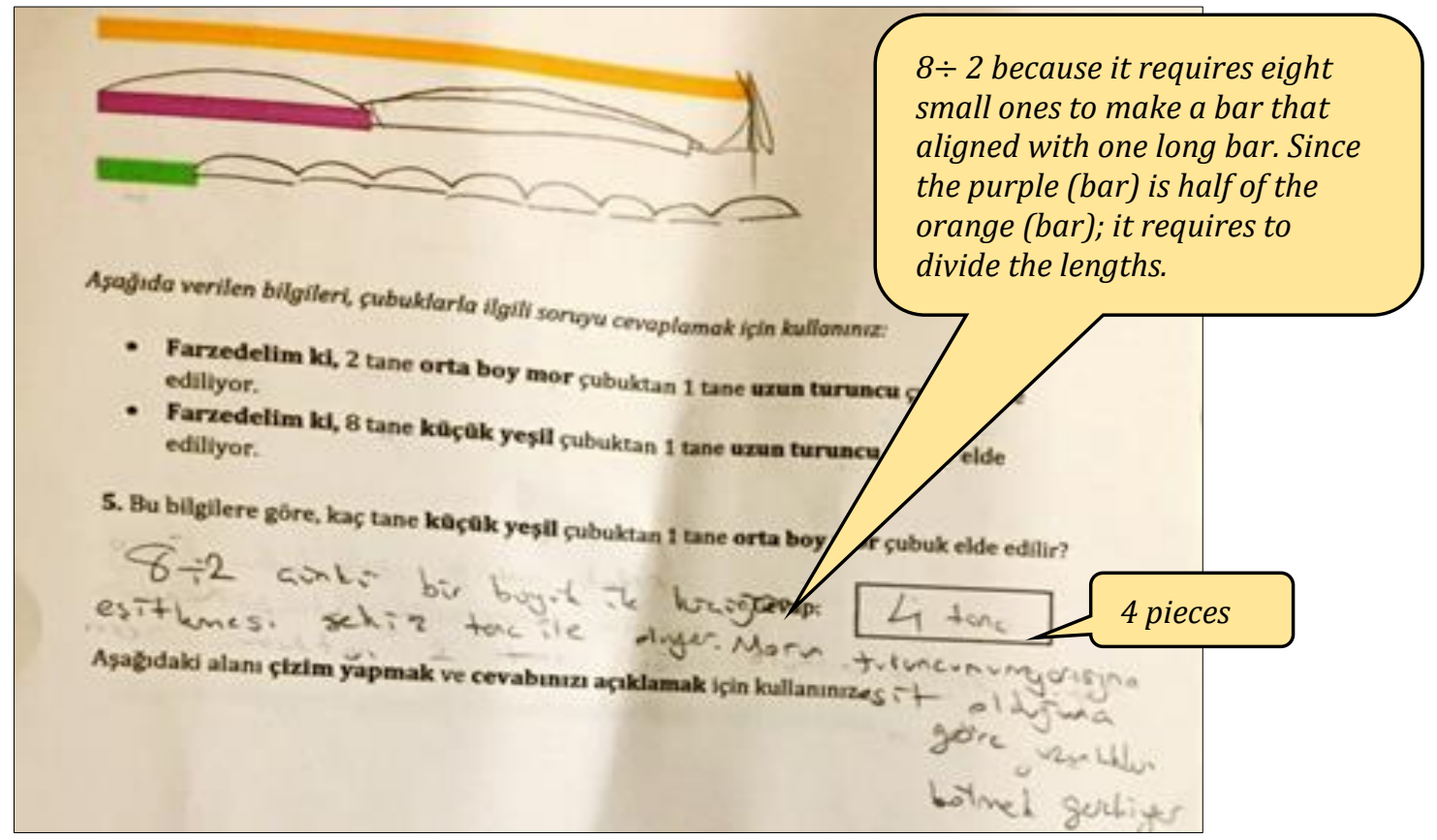

FIGURE 8. A sixth grader's response to Task 5 indicating Stage 3 
This student's response indicated his/her understanding of the multiplicative relationship in three levels of units (i.e., a composite unit of composite units) and his/her reverse multiplicative reasoning. S/he also provided the following explanation: "because it requires eight small ones to make a bar that aligned with one long bar. Since the purple (bar) is half of the orange (bar); it requires to divide the lengths." Another Stage 3 student justified the division operation by displaying three levels of unit coordination in drawings (see Figure 9).

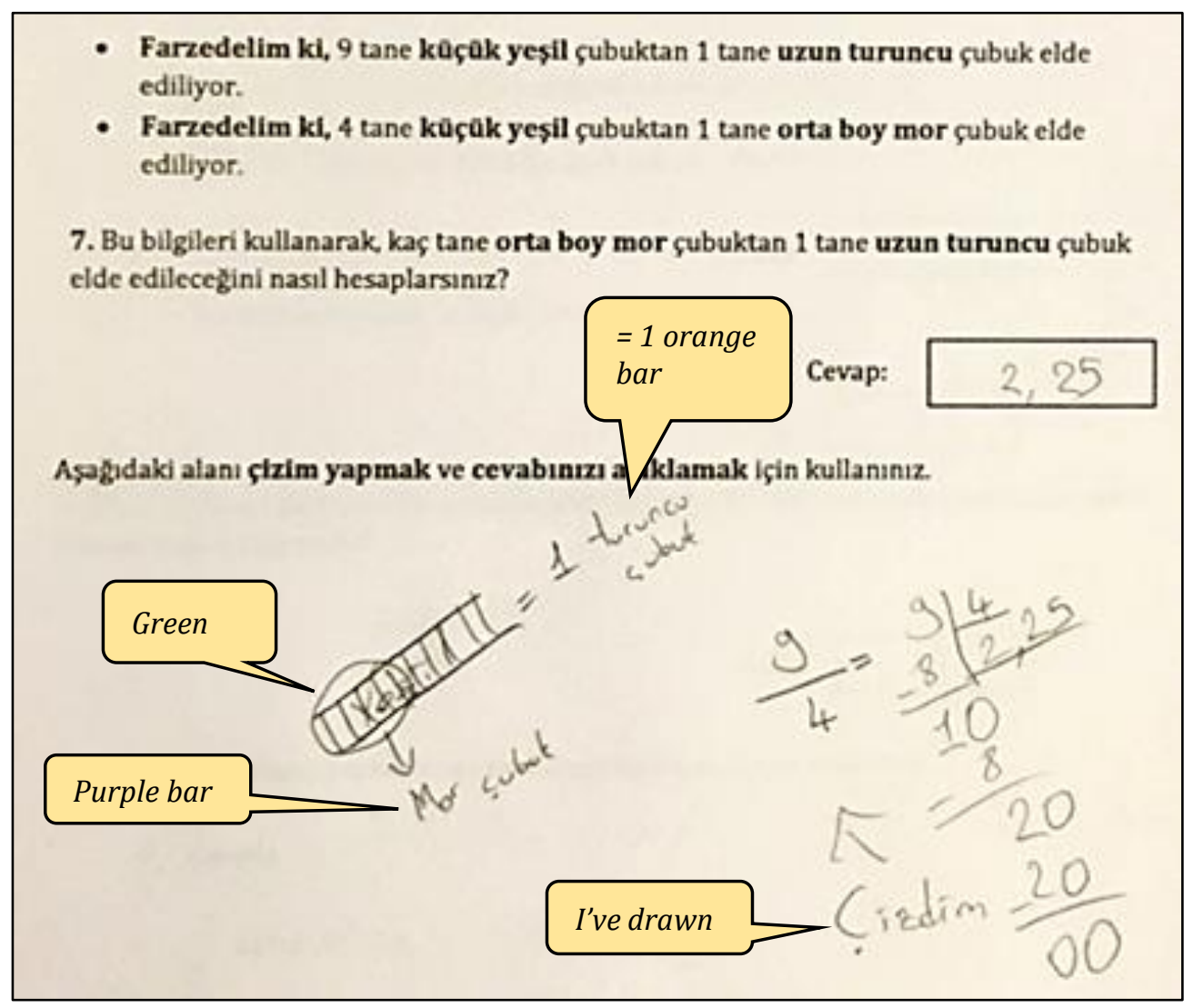

FIGURE 9. A sixth grader's response to Task 7 indicating Stage 3

As seen in Figure 9, this student showed a long orange bar as composed of two purple bars, each of which involved four green bars on a single picture (i.e., a unit of units of units). This picture demonstrated that s/he could maintain three levels of units at a time and used it to explain his/her solution.

\section{$7^{\text {th }}$ Grade Students' Unit Coordination Stages}

According to the overall assessment of 52 seventh graders, 25 students (48.1\%) were identified at Stage $1 ; 22$ students (42.3\%) were at Stage 2 , and five students (9.6\%) were characterized at Stage 3 (see Table 6).

The responses of 30 seventh grade students (57.7\%) indicated the same unit coordination level in all tasks in the test. 16 of these students responded to all tasks at Stage 1 and 14 of them at Stage 2. In addition, the responses of 11 students (21.2\%) included indicators of both Stage 1 and 2; 10 students (19.2\%) showed indicators of both Stage 2 and 3, and one student responded at all three stages throughout the test. Considering students' responses to $5^{\text {th }}, 6^{\text {th }}$, and $7^{\text {th }}$ tasks involving reverse multiplicative reasoning, the most frequent unit coordination level within the test was determined as 
the overall unit coordination stage. Seven of 11 students who responded at both Stage 1 and 2 were determined at Stage 1 in the overall assessment, while four of them were identified at Stage 2. Half of the students who responded at both Stage 2 and 3 were categorized at Stage 2 while the other half was recognized at Stage 3. Lastly, the student performed at different stages in different tasks was determined to be at Stage 2 .

Table 6. Seventh graders' unit coordination stages

\begin{tabular}{llll}
\hline \multicolumn{4}{c}{ Unit Coordination Stages } \\
\hline Tasks & Stage 1 & Stage 2 & Stage 3 \\
\hline $\mathbf{1 - - 3}$ & $24(46.2 \%)$ & $28(53.8 \%)$ & \\
$\mathbf{4}$ & $26(50.0 \%)$ & $26(50.0 \%)$ & $0(0 \%)$ \\
$\mathbf{5}$ & $25(48.1 \%)$ & $21(40.4 \%)$ & $6(11.5 \%)$ \\
$\mathbf{6}$ & $26(50.0 \%)$ & $14(26.9 \%)$ & $12(23.1 \%)$ \\
$\mathbf{7}$ & $32(61.5 \%)$ & $16(30.8 \%)$ & $4(7.7 \%)$ \\
\hline Overall Assessment & $25(48.1 \%)$ & $22(42.3 \%)$ & $5(9.6 \%)$ \\
\hline
\end{tabular}

Although the majority of the seventh graders responded at Stage 1 in almost all tasks, the percentage of Stage 1 students decreased at later tasks in the test. Similarly, the percentage of students at Stage 2 displayed a sharp decrease, while the number of students at Stage 3 increased from Task 5 to 6 . In general, we observed that half of the seventh graders in the study could not reach a unit coordination level in which they can assimilate and use multiplicative relationships. On the other hand, other students could take two levels of units as given and use them one by one to build up the third level of units (i.e., Stage 2). However, they were not in the level of comprehending a single three-level relation at a time, and they could not show multiplicative reasoning apparently in their solutions or explanations, which was seen in only 9.6 percent of seventh graders.

Almost all the Stage 1 students answered the tasks relying on the appearance of the bars. We also observed that a few students carried out addition or subtraction operations with the given numbers. In the rest of the Stage 1 responses, there were either no response or irrelevant calculations or drawings. Besides, we observed that the number of students operating at Stage 2 decreased toward the end of the test. The responses of Stage 2 students mostly involved multiplication or division operations without explanation or drawing to show their reasoning. Although some students did not show the operation on the paper, their answers involved correct procedure (i.e., multiplication or division). For example, in Task 4, requiring multiplication of 6 and 2, we inferred that the student mentally carried out multiplication by taking two levels of units as given. Hence, this solution presented the use of the given multiplicative relations and figuring out the third level unit (see Figure 10). As seen in Figure 10, the Stage 2 student represented the multiplicative relationship between the units by drawing and found the answer through those drawings without doing any arithmetic operation. In this response, we also observed that the student used algebraic expressions, indicating an understanding of the multiplicative relationship between unknown quantities.

Some other Stage 2 students, on the other hand, provided explanations in addition to the drawings. For example, a student showed her/his assimilation of two-level multiplicative relationship in Task 3 through the following explanation: "if one yellow bar was made up of three blue ones, four yellow bars was made up of 12 blue ones" even though s/he did not carry out an arithmetic operation. Furthermore, some students' responses included signs of proportional reasoning, although it was seen only procedurally. We infer that this might be because students learned ratio and proportion in the seventh-grade. Figure 11 presented such a case. In this student response, the student displayed 
the multiplicative relationship between green and orange and between green and purple bars. Then $\mathrm{s} /$ he built up the third ratio showing the multiplicative relationship between purple and orange by using previous ratios. The same student used the same strategy in other tasks as well.

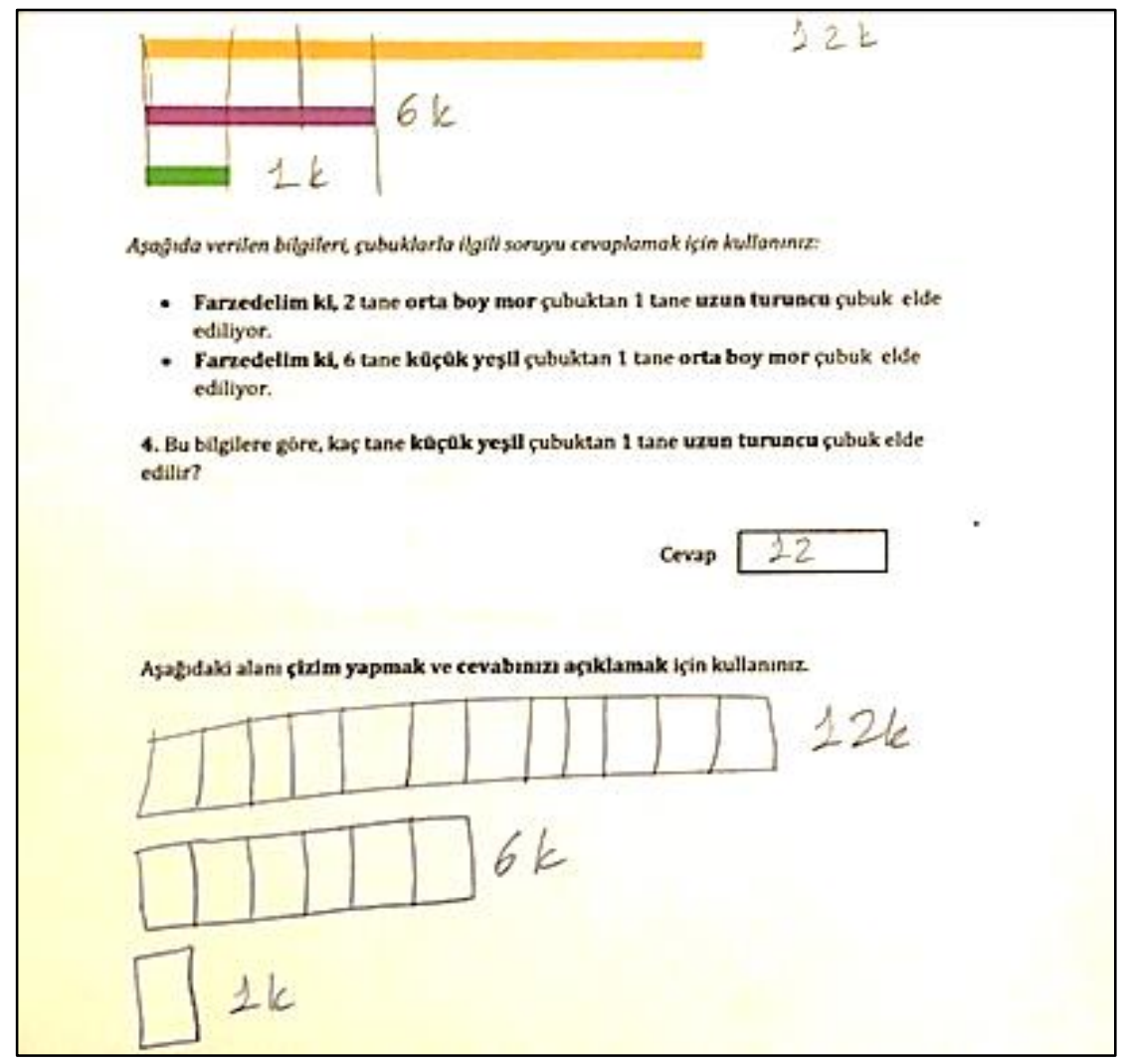

FIGURE 10. $A$ seventh grader's response to Task 4 indicating Stage 2

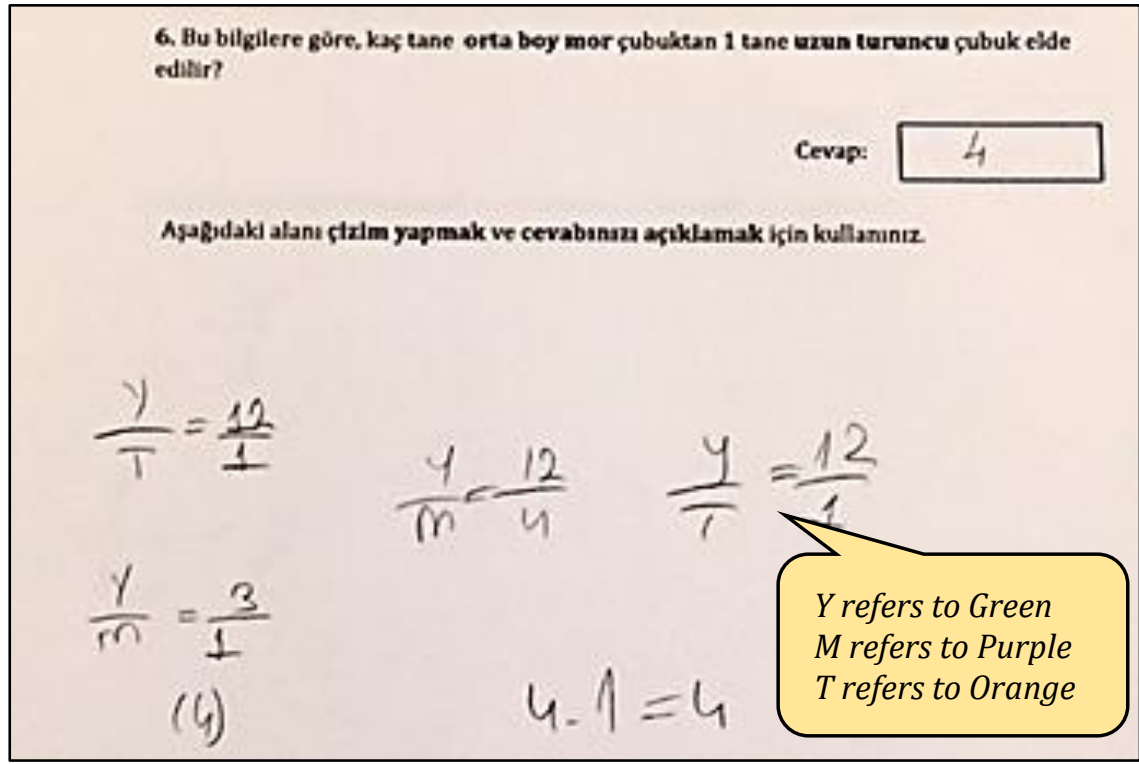

FIGURE 11. $A$ seventh grader's response to Task 6 indicating Stage 2 
Regarding Stage 3, the most apparent indicator was showing three level-units on a single picture or explaining why they did multiplication/division. A sample Stage 3 response was given in Figure 12. Student's drawing on Task 5 represented a three-level unit structure on a single picture involving the long orange bar split into two (i.e., two purple bars), each of which was split into four (i.e., four green bars). Therefore, her/his unit coordination level indicated Stage 3.

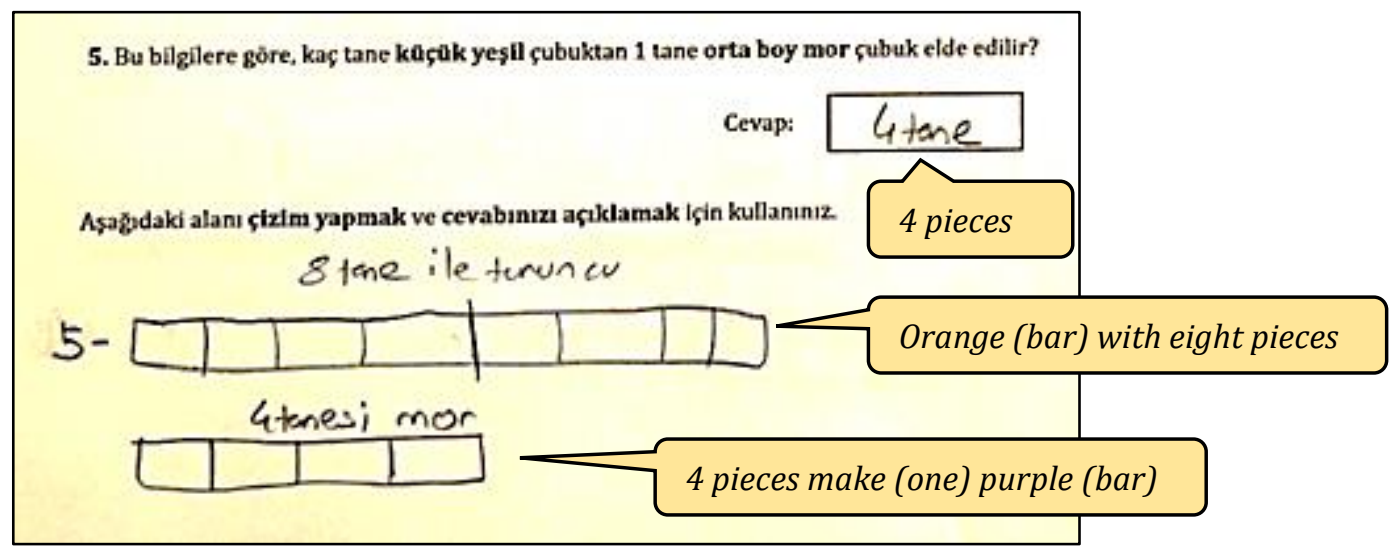

FIGURE 12. A seventh grader's response to Task 5 indicating Stage 3

Similar to the Stage 2 students, some of the Stage 3 students algebraically represented the multiplicative relations between units. For example, a student wrote " $\mathrm{x}, 4 \mathrm{x}, 9 \mathrm{x}$ " to describe the length of bars in Task 7 and answered the task as $2 \frac{1}{4}$. Viewing the multiplicative relations correctly and finding both the whole- and fractional-part of the response correctly were categorized as indicators of Stage 3. This response showed that s/he could interiorize three-levels of units at once and reversed her/his multiplicative reasoning. Another student response to Task 7 pointed out single three-level unit coordination through drawings (see Figure 13).

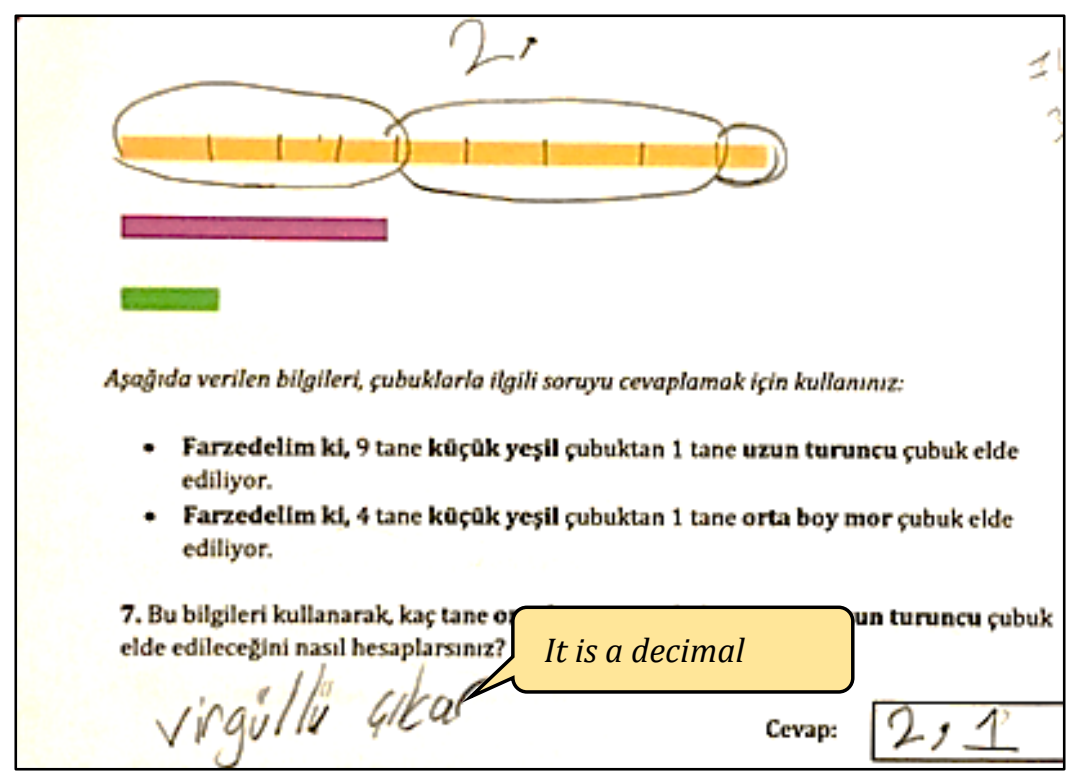

FIGURE 13. A seventh grader's response to Task 7 indicating Stage 3 
As seen in this student response, this student was determined at Stage 3 because s/he demonstrated three-level unit relations at a time on the picture despite the incorrect decimal-part of the response.

\section{$8^{\text {th }}$ Grade Students' Unit Coordination Stages}

Among the 41 eighth graders, we identified 14 (34.1\%) Stage 1 students, 25 (61.0\%) Stage 2 students, and two (4.9\%) Stage 3 students. 26 students responded to all tasks in the test at the same stage of unit coordination (i.e., 13 students at Stage 1, 11 students at Stage 2, and 2 students at Stage 3). Eight students demonstrated both Stage 1 and 2 indicators, and five students showed both Stage 2 and 3 indicators. For students showing indicators of multiple stages, the overall assessment was made considering the most frequent stages across the tasks in the test. Among the eight students who showed both Stage 1 and 2 indicators, one of them was identified at Stage 1; seven were at Stage 2. All five students who revealed both Stage 2 and 3 responses were determined to be at Stage 2 . Lastly, the unit coordination stages of two students whose responses indicated all three stages in different tasks were categorized at Stage 2. The eighth-grade students' unit coordination stages in each task and in the overall assessment were given in Table 7.

Table 7. Eighth graders' unit coordination stages

\begin{tabular}{llll}
\hline \multicolumn{4}{l}{ Unit Coordination Stages } \\
\hline Tasks & Stage 1 & Stage 2 & Stage 3 \\
\hline $\mathbf{1 - 3}$ & $17(41.5 \%)$ & $24(58.5 \%)$ & \\
$\mathbf{4}$ & $14(34.1 \%)$ & $25(61.0 \%)$ & $2(4.9 \%)$ \\
$\mathbf{5}$ & $14(34.1 \%)$ & $22(53.7 \%)$ & $5(12.2 \%)$ \\
$\mathbf{6}$ & $17(41.5 \%)$ & $21(51.2 \%)$ & $3(7.3 \%)$ \\
$\mathbf{7}$ & $23(56.1 \%)$ & $12(29.3 \%)$ & $6(14.6 \%)$ \\
\hline Overall Assessment & $14(34.1 \%)$ & $25(61.0 \%)$ & $2(4.9 \%)$ \\
\hline
\end{tabular}

As seen in Table 7, the general overview of the eighth-grade students' unit coordination stages showed that the number of students operating at Stage 2 was at the highest percentage in each task except the last one. Similar to the fifth, sixth, and seventh grade students, the percentage of eighthgraders at Stage 3 was the lowest. This finding indicated that more than half of the eighth-grade students could not develop conceptually flexible ways of maintaining three levels of units at once. However, they could coordinate the multiplicative relationship between pairs of the units and carry out the required operations in multiplicative situations.

Similar to the results in other grades, all Stage 1 students, except one who did subtraction, considered the appearance of bars on the paper. Eighth graders who performed at Stage 2 either carried out multiplication and/or division operations with or without explanations or represented the multiplicative relationship by drawing a picture. For example, a Stage 2 student showed the iteration of three green bars, counted as "3-6-9-12," and carried out a division operation afterward, as seen in Figure 14. Another student's response to Task 4 in Figure 15 demonstrated that s/he coordinated units through the drawings, a Stage 2 indicator. In this case, the student did not perform any operation, but s/he drew the number of units based on the given relations, which led to the correct answer. 


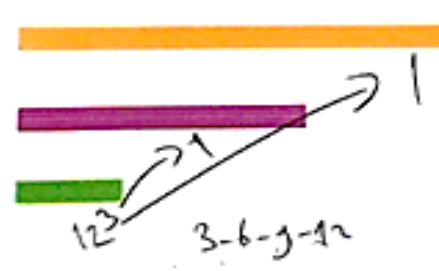

Asağıda verilen bilgileri, çubuklarla ilgilli soruyu cevaplamak için kullanını:

- Farzedelim ki, 12 tane kạ̧̧ak yeşll çubuktan 1 tane uzun turuncu çubuk elde ediliyor.

- Farzedellm ki, 3 tane küçük yeşll çubuktan 1 tane orta boy mor çubuk elde ediliyor.

6. Bu bilgilere gōre, kaç tane orta boy mor çubuktan 1 tane uzun turuncu çubuk elde edilir?

Cevap:

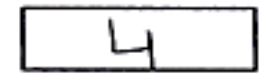

Aşă̊̆daki alanı çizim yapmak ve cevabınızı açıklamak için kullanınız.

$$
12 \div 3=4 \text { Bolman } 2 \text { orein }
$$
I need to divide

FIGURE 14. An eighth grader's response to Task 6 indicating Stage 2

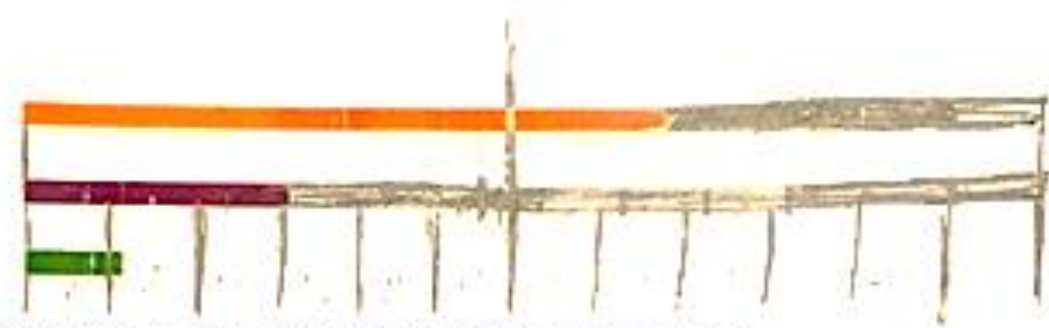

Yukanda verilęn renkli şbuklara gore aqabdaki soruyu ceraplayniz

4.

- Orta boy mor cubukua (tam olafak) 2 tane kutlanarak uxun turancu çub. olusturabildıgimizi đoşunelim.

- Kuçak yesil cubaktan [tam olarak) 6 tane kullasarak orta boy mor subuğ. olequarabildiğimizi đusunelim.

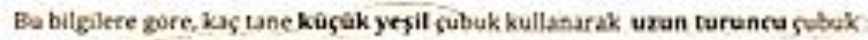
olusturabilecesimizi hesaplayniz.

By rule of thumb, I extended the bars. The reason why I extended the lengths of the bars was that it did not say 'don't extend' or Cevap

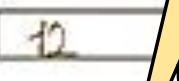
'don't shorten.'

Asakdaki alan sizim ydpmak ve cevabunzr acıklamak için kollanunx.

Gäs karan ve Gubukienn boyunu watorak ortalodim ve boyinu uzatma sebebimole bona kisaltina ya da usatma gibir seyler domiyo dmas.

FIGURE 15. An eighth grader's response to Task 4 indicating Stage 2 
Lastly, Stage 3 students either wrote their justifications for the operations they carried out or demonstrated three levels of units at the same time on a single picture. For instance, a student who stated "2 units of 6 units of green make 12 (units)" was identified as Stage 3. In the same task, another student was evaluated at Stage 3 because s/he could display three levels of units on a single picture (see Figure 16).

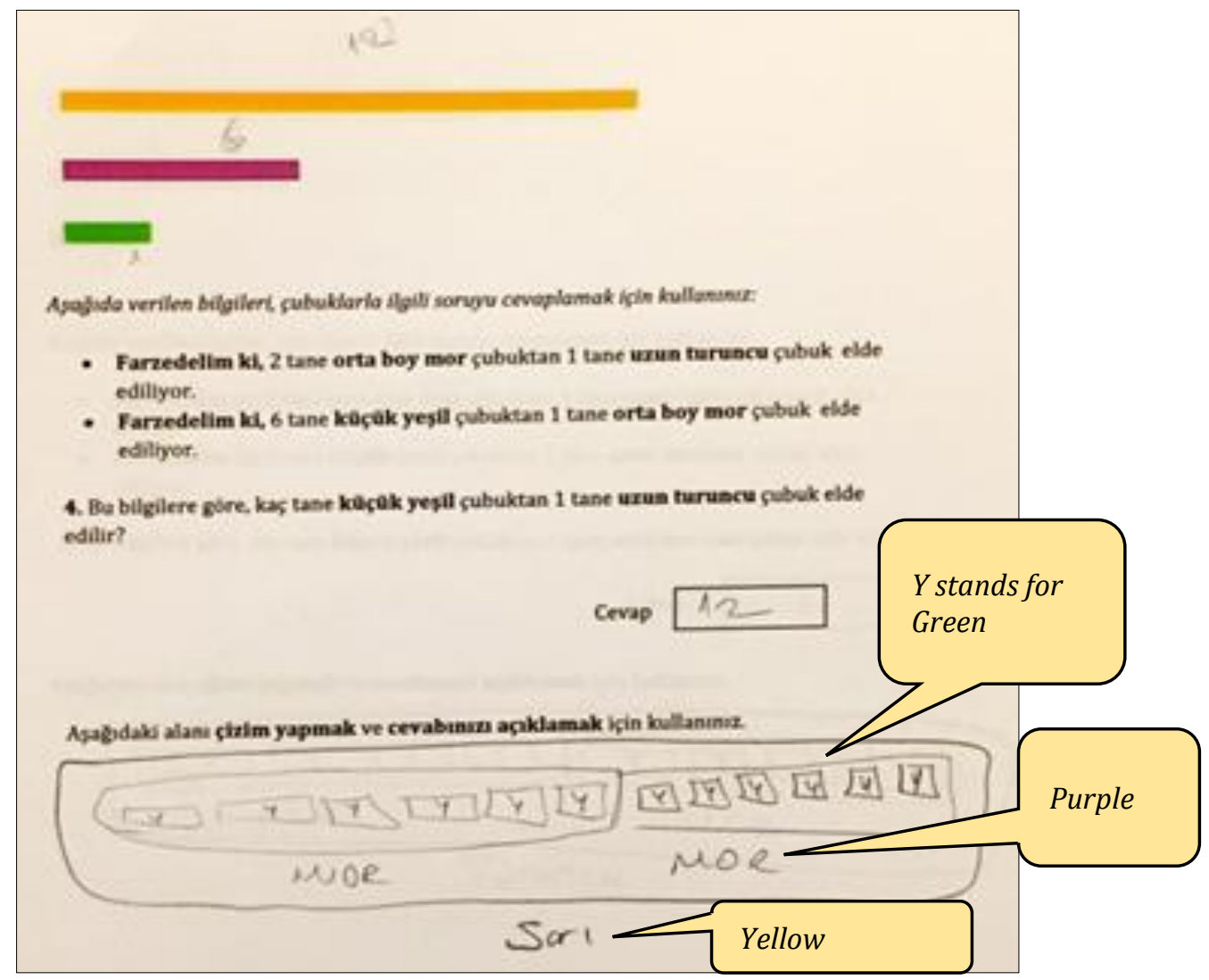

FIGURE 16. An eighth grader's response to Task 4 indicating Stage 3

In this student response, both the picture that s/he drew and the numbers, "1-6-12," that s/he wrote on the bars showed that the student could build up the three-level unit relationship. Similarly, another student expressed three levels of units at once by using algebraic expressions " $x-3 x-12 x$ " in Task 6.

\section{DISCUSSION AND CONCLUSION}

Researchers have emphasized the important role of unit coordination on students' understanding of many mathematics topics and investigated the stages of unit coordination (Hackenberg \& Tillema, 2009; Norton et al., 2015). In this study, we identified unit coordination levels of 139 Turkish middle school students and examined how students at different grade levels coordinated multiple levels of units in multiplicative situations.

The results of the study revealed that almost half of the middle school students $(47.5 \%)$ operated at Stage 2 of unit coordination. In other words, nearly half of the middle school students assimilated given two-level multiplicative relations and could coordinate three levels of units through either mental or physical activities (Norton et al., 2015). However, these students could not reach to the level of maintaining the three levels of units flexibly. Approximately the same percentage of students (44.6\%) participated in the study showed Stage 1 indicators of the unit coordination. This 
observation revealed that almost half of the middle school students could not assimilate the multiplicative relationship between the units, although they could view the composite units as a collection of ones. Lastly, a small percentage of middle school students (7.9\%) demonstrated unit coordination at Stage 3. That is, a few middle school students could assimilate the given multiplicative relationship as a unit of units of units and immediately switch between the unit structures.

When the findings were examined in terms of the grade level, we observed that students in each grade level demonstrated three stages of unit coordination. However, the number of students operating at Stage 3 was the lowest in all grade levels. In other words, a few middle school students could immediately take three levels of units as given. Another notable finding was that the number of Stage 1 students was the highest in all grades except Grade 8. This finding indicated that most of the students tended to rely on the physical appearance of the bars given in the tasks rather than paying attention to multiplicative relations between the bars. Stage 1 students' counting the iterated units they drew may also indicate their tendency to answer the task quickly and spending less time on reasoning.

Similarly, studies investigating students' intuitive ways of thinking in problem-solving revealed that students often used irrelevant information that was saliently given in the task instead of identifying relevant information among irrelevant ones (e.g., Babai, Levyadun, Stavy, \& Tirosh, 2006). Besides, the considerable number of Stage 1 students at lower grades in the current study supports the findings of the study conducted by Toluk Uçar and Bozkus (2016) on multiplicative reasoning. Specifically, the researchers found that students' multiplicative reasoning was not yet developed sufficiently in the lower middle school grades. Our study indicated that students' lowerlevel unit coordination led to difficulties in identifying multiplicative relation situations, and therefore students demonstrated additive reasoning.

Another finding of this study, the increase in the number of students operating at Stage 2 of unit coordination toward upper-grade levels, indicated an improvement in unit coordination levels of students, particularly in the eighth grade. Moreover, only one eighth-grader carried out addition/subtraction operations in multiplicative situations while, in other grade levels, at least five students were using additive reasoning, a Stage 1 indicator. This result pointed out that eight graders struggled less in identifying multiplicative and additive reasoning situations because eighth-graders made the most progress in terms of unit coordination levels compared to lower grades in middle school. These findings supported the claims of Toluk Ucar and Bozkus (2016) that upper-grade middle school students could use more multiplicative reasoning strategies while solving mathematics problems. Steffe (2007) also asserted that upper-grade students' flexible coordination of three-level units could be a consequence of the developmental progress of children.

Besides, we encountered seventh-grade students' usage of algebraic expressions or ratios. We infer that the mathematics topics (such as algebraic equations, ratio, and proportion) that were extensively taught in the seventh-grade mathematics program in Turkey (MNE, 2018) might have affected the students' solution strategies. Although algebraic and proportional relations indicated multiplicative relations, the memorized procedures that did not present explicit use of unit coordination were not categorized at Stage 3. However, the students who showed the lengths of bars using algebraic expressions involving the multiples of the same unknown referred to a single threelevel relation, an indication of Stage 3.

This study also showed that the responses of Stage 2 students often included multiplication and division operations without justification or explanation. For example, in Tasks 5 and 6, carrying out division indicated students' reversing the multiplicative reasoning, Stage 2 or 3 unit coordination (Hackenberg, 2010). Since failing to justify division operation might indicate students' memorized procedures rather than showing their assimilation of two levels of units, they were identified at Stage 2. Tasks 5 and 6 specifically asked the students to provide an explanation to reveal whether students were reversing multiplicative reasoning so that they could be identified at Stage 3. However, the student responses including multiplication/division operations without explanations might indicate 
students' reluctance to provide explanations on the written test even though these students might assimilate the relations between the composite units. Therefore, this study was limited with the written responses, and therefore we suggest carrying out interview studies to compare the findings with those reached in this study.

The findings of the study revealed that there was a considerable amount of students who could not coordinate multiple levels of units (i.e., a high percentage of Stage 1 students), informing us about students' difficulties in learning mathematics. Although the middle school mathematics program included many topics involving multiplicative relations, particularly starting in the sixth grade, almost half of the students in each grade level were determined at Stage 1. This finding indicated that almost half of the students in each grade level could not assimilate multiplicative relations between composite units. Considering that the lack of unit coordination influenced students' mathematics learning in other topics such as fractions, rational number, and algebra (e.g., Hackenberg, Aydeniz, et al., 2017; Hackenberg, Jones, et al., 2017; Ulrich \& Wilkins, 2017; Zwanch, 2019), the findings of this study suggest mathematics educators designing lessons that would improve students' unit coordination levels. We also suggest mathematics education researchers carrying out design-based studies testing the mathematics tasks that would develop students from Stage 1 to Stage 3 of unit coordination. Furthermore, we believe that the results of this study may inform curriculum developers and lead to revisions in the middle school mathematics program regarding students' unit coordination stages.

In this study, we elicited the unit coordination levels of students from an accessible middle school in Turkey. Therefore, another limitation of the study was the limited number of students in only one middle school. Therefore, as further research, we recommend a replication study with more middle school students in different regions in Turkey, which may provide a complete picture of the phenomenon and more generalizable findings. The written test in assessing the unit coordination levels of students allows conducting studies with more participants in an extensive study. However, conducting interviews with some students would help to reduce the difficulties encountered in deciding the unit coordination stages of students and might increase the validity of the overall assessments. Hence, we suggest researchers' supporting the coded answers in the written test by interviews with the students.

\section{REFERENCES}

Akkuş-Çıkla, O. ve Duatepe, A. (2002). İlköğretim matematik öğretmen adaylarının orantısal akıl yürütme becerileri üzerine niteliksel bir çalışma, Hacettepe Ĕ̆itim Fakültesi Dergisi, 23, 32-40.

Babai, R., Levyadun, T., Stavy, R., \& Tirosh, D. (2006). Intuitive rules in science and mathematics: A reaction time study. International Journal of Mathematical Education in Science and Technology, 37(8), 913-924.

Boyce, S., \& Norton, A. (2016). Co-construction of fractions schemes and units coordinating structures. The Journal of Mathematical Behavior, 41, 10-25.

Creswell, J. W. (2007). Qualitative inquiry and research design: Choosing among five approaches (2nd ed.). Thousand Oaks, CA, US: Sage Publications, Inc.

Hackenberg, A. J. (2007). Units coordination and the construction of improper fractions: A revision of the splitting hypothesis. The Journal of Mathematical Behavior, 26(1), 27-47.

Hackenberg, A. J. (2010). Students' reasoning with reversible multiplicative relationships. Cognition and Instruction, 28(4), 383-432.

Hackenberg, A. J. (2013). The fractional knowledge and algebraic reasoning of students with the first multiplicative concept. The Journal of Mathematical Behavior, 32, 538-563.

Hackenberg, A. J., Aydeniz, F., Jones, R., \& Borowksi, R. (2017). Students' meaning for extensive quantitative unknowns. In Galindo, E. \& Newton, J. (Eds.), Proceedings of the Thirty-ninth Annual Meeting of the North American Chapter of the International Group for the Psychology of Mathematics Education (pp. 311-314). Indianapolis, IN: Hoosier Association of Mathematics Teacher Educators 
Hackenberg, A. J., Jones, R., Eker, A., \& Creager, M. (2017). “Approximate" multiplicative relationships between quantitative unknowns. The Journal of Mathematical Behavior, 48, 38-61. DOI:10.1016/j.jmathb.2017.07.002

Hackenberg, A. J., \& Lee, M. Y. (2015). How does students' fractional knowledge influence equation writing? Journal for Research in Mathematics Education,46(2), 199-243.

Hackenberg, A. J., Norton, A. H., \& Wright, R. J. (2016). Developing fractions knowledge. London: SAGE.

Hackenberg, A. J. \& Sevinç, S. (under review). The Construction of Reciprocal Reasoning with Quantitative Unknowns.

Hackenberg, A. J., \& Tillema, E. S. (2009). Students' whole number multiplicative concepts: A critical constructive resource for fraction composition schemes. Journal of Mathematical Behavior 28, 1-18.

Lamon, S. J. (2007). Rational numbers and proportional reasoning: toward a theoretical framework for research. In F. K. Lester Jr. (Ed.), Second handbook of research on mathematical teaching and learning (pp. 629667). Reston: National Council of Teachers of Mathematics.

Ministry of National Education (MNE). (2018). Elementary and Middle School Mathematics Program: Grades 1, $2,3,4,5,6,7$, and 8 . Ankara: Ministry of National Education.

Norton, A., \& Boyce, S. (2013). A cognitive core for the common state standards. The Journal of Mathematical Behavior, 32(2), 266-279.

Norton, A., Boyce, S., Phillips, N., Anwyll, T., Ulrich, C., \& Wilkins, J. L. M. (2015). A written instrument for assessing students' units coordination structures. Mathematics Education, 10(2), 111-136.

Reynolds, A., \& Wheatley, G. H. (1996). Elementary students' construction and coordination of units in an area setting. Journal for Research in Mathematics Education, 27 (5) 564-581. DOI:10.2307/749848

Steffe, L. P. (1992). Schemes of action and operation involving composite units. Learning and Individual Differences, 4(3), 259-309.

Steffe, L. P. (2007, April). Problems in mathematics education. Paper presented for the Senior Scholar Award of the Special Interest Group for Research in Mathematics Education (SIG-RME) at the annual conference of the American Educational Research Association in Chicago, Illinois.

Steffe, L. P., \& Olive, J. (2010). Children's fractional knowledge. New York: Springer.

Toluk- Uçar, Z., \& Bozkuş, F. (2016). İlkokul ve ortaokul öğrencilerinin orantısal durumları orantısal olmayan durumlardan ayırt edebilme becerileri. Ahi Evran Üniversitesi Kırșehir Eğitim Fakültesi Dergisi (KEFAD), 17(3). 281-299.

Tzur, R., Johnson, H. L., Norton, A., Davis, A., Wang, X., Ferrara, M., Jorgensen, C. \& Wei, B. (2017). Conception of number as a composite unit predicts students' multiplicative reasoning: Quantitative corroboration of Steffe's model. In B. Kaur, W. K. Ho, T. L. Toh, \& B. H. Choy (Eds.), Proceedings of the 41st Conference of the International Group for the Psychology of Mathematics Education (Vol. 4, pp. 289-296). Singapore: PME.

Ulrich, C. (2015). Stages in constructing and coordinating units additively and multiplicatively (Part 1). For the Learning of Mathematics, 35(3), 2-7.

Ulrich, C., \& Wilkins, J. L. M. (2017). Using written work to investigate stages in sixth-grade students' construction and coordination of units. International Journal of STEM Education, 4(23), 1-20. https://doi.org/10.1186/s40594-017-0085-0

VERBI Software. (2017). MAXQDA 2018 [computer software]. Berlin, Germany: VERBI Software. Available from https://www.maxqda.com

Watanabe, T. (1995). Coordination of units and understanding of simple fractions: Case studies. Mathematics Education Research Journal, 7(2), 160-175.

Yin, R. K. (2003). Case study research: Design and methods. Thousand Oaks, CA: Sage.

Zwanch, K. (2019). Using number sequences to model middle-grades students' algebraic representations of multiplicative relationships. In Otten, S., Candela, A. G., de Araujo, Z., Haines, C., \& Munter, C. (Eds.), Proceedings of the forty-first annual meeting of the North American Chapter of the International Group for the Psychology of Mathematics Education (pp. 177-185). St Louis, MO: University of Missouri. 
APPENDIX A

Unit Coordination Test

Name:

Teacher:

Date:

Use the bars shown above to answer the following three questions:

1. How many times does the Medium Yellow Bar fit into the Long Red Bar?

answer:

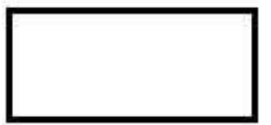

2. How many times does the Small Blue Bar fit into the Medium Yellow Bar?

answer:

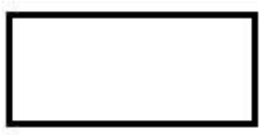

3. Use this information to figure out how many times the Small Blue Bar fits into the Long Red Bar?

answer:

Use the space below to draw a picture and explain your answer. 
Date:

Use the following information to answer questions about the bars shown above:

4. Pretend that the Medium Purple Bar fits into the Long Orange Bar exactly 2 times.

Pretend that the Small Green Bar fits into the Medium Purple Bar exactly 6 times.

Use this information to figure out how many times the Small Green Bar would fit into the Long Orange Bar?

answer:

Use the space below to draw a picture and explain your answer.

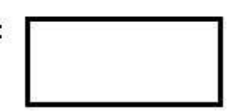
Name:
Teacher:
Date:

Use the following information to answer questions about the bars shown above:

5. Now pretend that the Medium Purple Bar fits into the Long Orange Bar exactly 2 times.

Pretend that the Small Green Bar fits into the Long Orange Bar exactly 8 times. Use this information to figure out how many times the Small Green Bar would fit into the Medium Purple Bar?

answer:

Use the space below to draw a picture and explain your answer. 
Name:

Teacher:

Date:

Use the following information to answer questions about the bars shown above:

6. Now pretend that the Small Green Bar fits into the Long Orange Bar exactly 12 times.

Pretend that the Small Green Bar fits into the Medium Purple Bar exactly 3 times.

Use this information to figure out how many times the Medium Purple Bar would fit into the Long Orange Bar?

answer:

Use the space below to draw a picture and explain your answer.

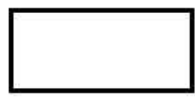

Name:

Teacher:

Date:

Use the following information to answer questions about the bars shown above:

7. Now pretend that the Small Green Bar fits into the Long Orange Bar exactly 9 times.

Pretend that the Small Green Bar fits into the Medium Purple Bar exactly 4 times.

How can you use this information to figure out how many times the Medium Purple Bar would fit into the Long Orange Bar?

answer:

Use the space below to draw a picture and explain your answer. 